ICAMS 2016 $-6^{\text {th }}$ International Conference on Advanced Materials and Systems

\title{
HEAVY METALS REMOVAL FROM CONTAMINATED WATER USING POLY(ACRYLAMIDE-CO-ACRYLIC ACID)-SODIUM ALGINATE FLOCCULANT OBTAINED BY ELECTRON BEAM IRRADIATION
}

\author{
ELENA MĂNĂILĂ $\breve{1}^{1}$, GABRIELA CRĂCIUN ${ }^{1 *}$, DANIEL IGHIGEANU ${ }^{1}$, MARIA DANIELA \\ STELESCU ${ }^{2}$ \\ ${ }^{1}$ National Institute for Laser, Plasma and Radiation Physics, Electron Accelerators Laboratory, \\ 409 Atomistilor St., 077125 Magurele, Romania, elena.manaila@infl.ro, "corresponding author: \\ gabriela.craciun@inflpr.ro \\ ${ }^{2}$ INCDTP - Division Leather and Footwear Research Institute, 93 Ion Minulescu St., Bucharest, \\ Romania
}

\begin{abstract}
The goal of the paper is to present the obtaining, characterization and testing of a new type of polyelectrolyte based on acrylamide, acrylic acid and sodium alginate for flocculation purposes. Polyelectrolytes, also called flocculants, were obtained by electron beam irradiation in atmospheric conditions and at room temperature. They have been characterized using various physical and chemical methods in order to determine conversion coefficient, residual monomer content, intrinsic viscosity and molecular weight. The heavy metals removal $\left(\mathrm{Cu}^{2+}\right.$ and $\left.\mathrm{Cr}^{6+}\right)$ was evaluated at room temperature on synthetic water having the contents of $0.05 \mathrm{wt} / \mathrm{vol} \% \mathrm{CuSO}_{4}$ and $0.05 \mathrm{wt} / \mathrm{vol} \% \mathrm{~K}_{2} \mathrm{Cr}_{2} \mathrm{O}_{7}$, respectively.
\end{abstract}

Keywords: flocculants, heavy metals, electron beam

\section{INTRODUCTION}

Over the past decades, increasing effort has been concentrated on developing various methods that can effectively remove heavy metal ions from aqueous environments. There are many methods for removing heavy metals that include chemical precipitation adsorbents (Meunier et al., 2006), membrane filtration adsorbents (Bessbousse et al., 2008), ion exchange adsorbents (Alyuz and Veli, 2009), liquid extraction adsorbents (Sprynskyy, 2009), reverse osmosis adsorbents (Liu et al., 2008), activated carbon adsorption adsorbents (Ucer et al., 2006) and the use of biopolymer adsorbents (Guclu et al., 2003). The removal can be accomplished by gravitation (very slow), by coagulation (dependent on electric charge situation) and by flocculation (not dependent on electric charges and the fastest) (Brostow et al. 2009). Coagulation is the phenomenon in which the system consisting of colloidal particles from water is destabilized. Flocculation is the phenomenon in which destabilized colloidal particles join together in larger agglomerations. It is caused by the addition of small quantities of chemicals known as flocculants and the effectiveness is manifested especially in the situations where colloidal particles are already destabilized. Flocculants are of two types, i.e., inorganic and organic. The organic flocculants are essentially polymeric in nature. Both, synthetic and natural water soluble polymers are used as flocculants. The synthetic polymers are mostly linear and water soluble, such as polyacrylamide, polyacrylic acid, poly(diallyl dimethyl ammonium chloride) or poly(styrene sulphonic acid). They are available in all the three forms, i.e., cationic, anionic and non-anionic. High molecular weight synthetic polymers like polyacrylamides are very effective flocculating agents. However these polymers are quite unstable in shear fields and hence lose their flocculation effectiveness. The natural polymers like polysaccharides exhibit good resistance to shear degradation, but they are less effective flocculating agents compared with synthetic polymers and their aqueous solutions are also susceptible towards biodegradation (Tripathy and De, 2007). 
Heavy Metals Removal from Contaminated Water using Poly(Acrylamide-co-

Acrylic Acid)-Sodium Alginate Flocculant Obtained by Radiation Processing

The goal of the paper is to present the obtaining, characterization and testing of a new type of flocculant based on acrylamide, acrylic acid and sodium alginate for flocculation purposes. In the present study, the alginate - one of the most nontoxic sulphated polysaccharides - has been chosen as a backbone. The flocculants were obtained by electron beam irradiation (EB) using doses in the range of $2 \mathrm{kGy}$ to $10 \mathrm{kGy}$ in atmospheric conditions and at room temperature. They were characterized by various physical and chemical methods in order to determine conversion coefficient, residual monomer content, intrinsic viscosity, molecular weight and radius of gyration. The heavy metals $\left(\mathrm{Cu}^{2+}\right.$ and $\left.\mathrm{Cr}^{6+}\right)$ removal efficacy was evaluated at room temperature.

\section{EXPERIMENTAL}

\section{Materials}

In order to obtain the flocculants, the following materials have been used: acrylamide - AMD (molar mass of $71.08 \mathrm{~g} \mathrm{~mol}^{-1}$; density of $1.13 \mathrm{~g} / \mathrm{cm}^{3}$ ); acrylic acid AA (molar mass of $72.06 \mathrm{~g} \mathrm{~mol}^{-1}$; density of $1.051 \mathrm{~g} / \mathrm{mL}$ ), sodium alginate - SA (molar mass of $216.12 \mathrm{~g} \mathrm{~mol}^{-1}$ ) and potassium persulfate (molar mass of $270.322 \mathrm{~g} \mathrm{~mol}^{-1}$; density of $2.477 \mathrm{~g} / \mathrm{cm}^{3}$ ) - used as initiator in the copolymerization process. All materials were from E-Merck, Germany.

\section{Preparation and Irradiation of the Samples}

Two different types of aqueous solutions based on acrylamide, acrylic acid and sodium alginate for the irradiation experiments were prepared: (a) the first type based on acrylamide ( $20 \mathrm{wt} / \mathrm{vol} \%$, acrylic acid $20 \mathrm{vol} / \mathrm{vol} \%$ and sodium alginate $2 \mathrm{wt} / \mathrm{vol} \%$ ) noted POL-I and (b) the second type on acrylamide (20 wt/vol \%, acrylic acid 20 $\mathrm{vol} / \mathrm{vol} \%$, sodium alginate $2 \mathrm{wt} / \mathrm{vol} \%$ and sodium persulphate $0.2 \mathrm{wt} / \mathrm{vol} \%$ ) noted POL-II. Each mixture was stirred at $250 \mathrm{rpm}$ at room temperature for $30 \mathrm{~min} .5 \mathrm{ml}$ from each type of solution was then transferred into $50 \mathrm{~cm}^{3}$ glass tubes and irradiated using electron beam with various doses in atmospheric conditions and at room temperature of $25^{\circ} \mathrm{C}$. Electron beam dose rate was fixed at $2 \mathrm{kGy} / \mathrm{min}$ in order to accumulate irradiation doses between 2-10 kGy.

\section{Experimental Installation and Sample Irradiation}

Experiments were carried out with an experimental installation consisting mainly of the following units: an electron linear accelerator (ALIN-10) of $6.23 \mathrm{MeV}$ energy and $75 \mathrm{~mA}$ peak current of the electron beam and an irradiation chamber containing the samples of monomer solution. The optimum values of the $\mathrm{EB}$ peak current $\mathrm{I}_{\mathrm{EB}}$ and $\mathrm{EB}$ energy $\mathrm{E}_{\mathrm{EB}}$ to produce maximum output power $\mathrm{P}_{\mathrm{EB}}$ for a fixed pulse duration $\tau_{\mathrm{EB}}$ and repetition frequency $\mathrm{f}_{\mathrm{EB}}$ are as follows: $\mathrm{E}_{\mathrm{EB}}=6.23 \mathrm{MeV}, \mathrm{I}_{\mathrm{EB}}=75 \mathrm{~mA}, \mathrm{P}_{\mathrm{EB}}=164 \mathrm{~W}\left(\mathrm{f}_{\mathrm{EB}}\right.$ $=100 \mathrm{~Hz}, \tau_{\mathrm{EB}}=3.5 \mathrm{~s}$ ). The EB effects are related to the absorbed dose (D) expressed in Gray or $\mathrm{J} \mathrm{kg}^{-1}$ and absorbed dose rate $\left(\mathrm{D}^{*}\right)$ expressed in Gy s${ }^{-1}$ or $\mathrm{J} \mathrm{kg}^{-1} \mathrm{~s}^{-1}$.

\section{Sample Characterization (Physical and Chemical Characteristics)}

In order to determine the conversion coefficient (CC) and the residual monomer concentration $\left(\mathrm{M}_{\mathrm{r}}\right)$, 2 grams of polymer (flocculant) were placed in $200 \mathrm{ml}$ distilled water for 24 hours and then every sample was stirred for 1 hour at $400 \mathrm{rpm}$ to ensure a very well mixing. $\mathrm{CC}$ and $\mathrm{M}_{\mathrm{r}}$ were determined by titrimetric method. The intrinsic viscosity $\left(\eta_{\text {intr. }}\right)$ 
ICAMS $2016-6^{\text {th }}$ International Conference on Advanced Materials and Systems

and the Huggin's constant $\left(\mathrm{k}_{\mathrm{H}}\right)$ were determined by the viscosity measurements, using the Hoppler type BH-2. Hoppler viscometer is a falling ball one. The measured parameter is the time of fall of the ball in a cylindrical tube inclined by 10 deg with respect to the vertical plane and filled with the liquid subjected to investigation. The principle of fallingball viscosimeters is based on the fact that the viscosity of liquid modifies the speed of the ball falling through this liquid. The time of fall of the ball through the polymeric solution was measured for five different concentrations. As a solvent, the sodium nitrate $1 \mathrm{~N}$ $\left(\mathrm{NaNO}_{3}\right)$ was used and the working temperature was of $30^{\circ} \mathrm{C}$. Using the time of fall of the ball through the polymeric solution ( $\mathrm{t}$ ) and the time of fall of the ball through the solvent $\left(\mathrm{t}_{0}\right)$ the relative viscosity was obtained:

$\eta_{\text {rel. }}=t / t_{0}$

Specific viscosity was calculated from the relation:

$\eta_{s p .}=\left(\eta_{\text {rel. }}-1\right)$

Reduced viscosity was determined using the relation:

$\eta_{\text {red. }}=\eta_{s p .} / c$

where $c$ is the polymer concentration $(\mathrm{g} / \mathrm{dL})$.

From the graphical representation of the $\eta_{\text {red }}$ as a function of the copolymer concentration, by extrapolation, was obtained the intrinsic viscosity $\eta_{\text {intr }}$ and $\operatorname{tg} \alpha$. Linearity constant was determined from the following relation:

$k_{H}=\operatorname{tg} \alpha /\left[\eta_{\text {int } r}\right]^{2}$

Intrinsic viscosity is a measure of the hydrodynamic volume occupied by the individual polymer molecules in isolation (Richardson and Kasapis, 1998). In dilute solutions, the polymer chains are separate and the $\left[\eta_{\text {intr }}\right]$ of a polymer in solution depends only on the dimensions of the polymer chain. From the Mark-Houwink equation, the relationship among the molecular weight and viscosity is given below:

$[\eta]=K \times M_{w}^{a}$

where $[\eta]$ is the intrinsic viscosity $(\mathrm{dl} / \mathrm{g}), \mathrm{M}_{\mathrm{w}}$ is viscosity average molecular weight, $\mathrm{K}$ and $a$ are constants for a particular polymer - solvent system ( $\mathrm{K}$ and $a$ are $3.73 * 10^{-4}$ and 0.66 in $1 \mathrm{~N}$ aqueous sodium nitrate at $30^{\circ} \mathrm{C}$ ) (Richardson and Kasapis, 1998; Zeynali and Rabbii, 2002).

\section{Flocculation Studies}

Water samples containing $\mathrm{Cu}^{2+}$ and $\mathrm{Cr}^{6+}$ were synthesized using $\mathrm{CuSO}_{4} * 5 \mathrm{H}_{2} \mathrm{O}(0.1$ $\mathrm{mol} / \mathrm{l}), \mathrm{K}_{2} \mathrm{Cr}_{2} \mathrm{O}_{7}(0.05 \mathrm{wt} / \mathrm{vol} \%)$, kaoline $(0.2 \mathrm{wt} / \mathrm{vol} \%)$ and distilled water. The jar test apparatus (Velp FC 6S, Italy) consists of 6 stirrer blades connected to a variable speed (0$100 \mathrm{rpm}$ ) motor through a gear system. In each beaker, $500-\mathrm{mL}$ of synthetic water (with $\mathrm{Cu}^{2+}$ or $\mathrm{Cr}^{6+}$ ) was taken and placed on the flocculator. Under a slow stirring condition, the polymer solution was added by means of a pipette in order to determine the polymer concentration influence (5-20 ppm). Immediately after the addition of polymer solution, the suspensions were stirred at a constant speed of $60 \mathrm{rpm}$ for $15 \mathrm{~min}$, and than allowed to sediment for $15 \mathrm{~min}$. Clear supernatant was drawn from the top layer (up to depth 1-2 cm) and its absorbance at $275 \mathrm{~nm}$ for $\mathrm{Cu}^{2+}$ (Wen et al., 2013) and $540 \mathrm{~nm}$ for $\mathrm{Cr}^{6+}$ (Iva and Zeiner, 2008) was measured using the Cary Bio-100 UV-VIS spectrophotometer. The heavy metals $\left(\mathrm{Cu}^{2+}\right.$ and $\left.\mathrm{Cr}^{6+}\right)$ removal was evaluated from the calibration curves. For dilute solutions, there is a linear relationship between absorbance and concentration. 


\section{RESULTS AND DISCUSSION}

\section{Physical and Chemical Characteristics}

In Figures 1-5 are represented the conversion coefficient (CC), the residual monomer concentration $\left(\mathrm{M}_{\mathrm{r}}\right)$, the intrinsic viscosity $\left(\eta_{\text {intr. }}\right)$, the linearity constant $\left(\mathrm{k}_{\mathrm{H}}\right)$ and the molecular weight $\left(\mathrm{M}_{\mathrm{w}}\right)$ depending on the absorbed dose, for all the 10 samples subjected to electron beam irradiation.

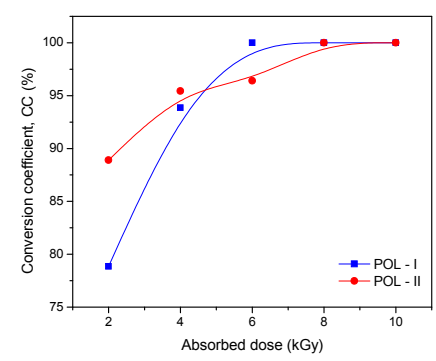

Figure 1. Conversion coefficient of the flocculants versus EB absorbed dose

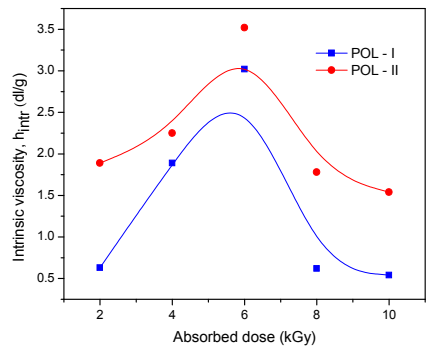

Figure 3. Intrinsic viscosity of the flocculants versus EB absorbed dose

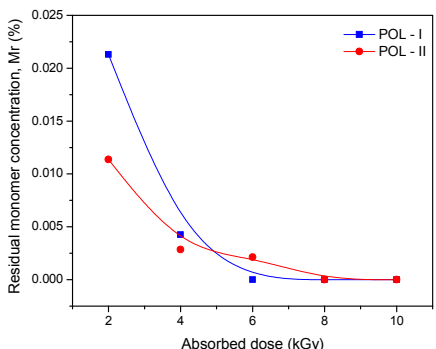

Figure 2. Residual monomer concentration of the flocculants versus EB absorbed dose

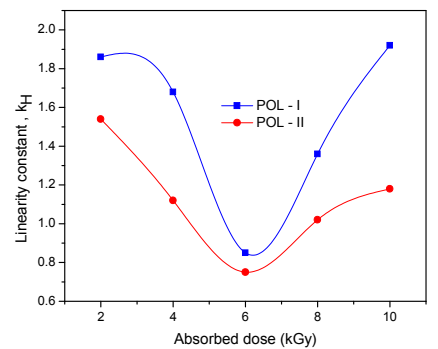

Figure 4. Linearity constant of the flocculants versus EB absorbed dose

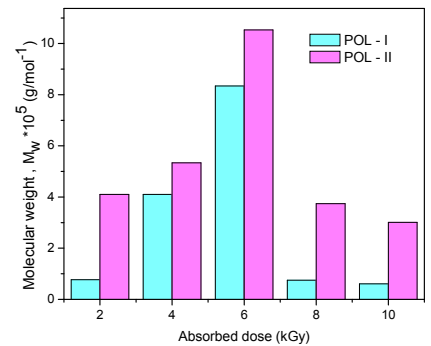

Figure 5. Molecular weight of the flocculants versus EB absorbed dose

The solutions subjected to EB irradiation have lead to the obtaining of polymers having relatively high conversion coefficients and molecular weights, especially at the upper limit of the used dose range ( $2 \mathrm{kGy}-10 \mathrm{kGy})$. Also, all the samples have presented low residual monomer in the polymer $(<0.05 \%$, which is the limit imposed by 
ICAMS $2016-6^{\text {th }}$ International Conference on Advanced Materials and Systems

the standards of use of AMD as a flocculant) and a good linearity. It was found that the $\mathrm{CC}$ has increased with increasing of absorbed dose. The probability of molecular contact became higher with increasing of the absorbed dose, more polymer molecules react, resulting in the propagation of the active chain and the continuously $\mathrm{CC}$ increasing. Intrinsic viscosity of a polymer is indicative of its hydrodynamic volume in solution, which depends on its molecular weight, structure and nature of the solvent as well as the temperature of the medium. For two polymers with approximately similar molecular weights, the branched polymer has lower hydrodynamic volume compared to its linear counterpart and thus has lower intrinsic viscosity value. Furthermore, long branches determine higher intrinsic viscosity and vice versa (Xie et al., 2009).

\section{Flocculation Results}

By UV-VIS spectrophotometry it is possible to easily determine the concentration of different heavy metals from water samples. The disadvantage is the relatively low linear working range, as can be observed in Figure 6. Two types of samples have been tested for $\mathrm{Cu}^{2+}$ and $\mathrm{Cr}^{6+}$ removal: POL - I and POL - II, both obtained at $6 \mathrm{kGy}$. We chose to use these samples, because all physical properties have maximum values. The results are presented in Figure 7. The $\mathrm{Cu}^{2+}$ and $\mathrm{Cr}^{6+}$ removal from synthetic water was done by determining the concentration of both metals from water using the spectrophotometric method and calibration curves.

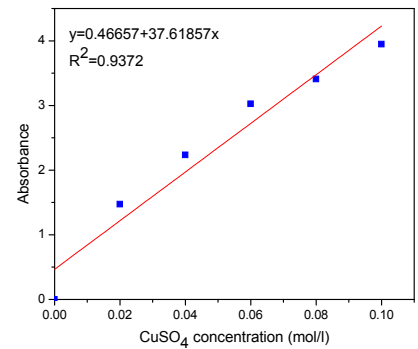

(a)

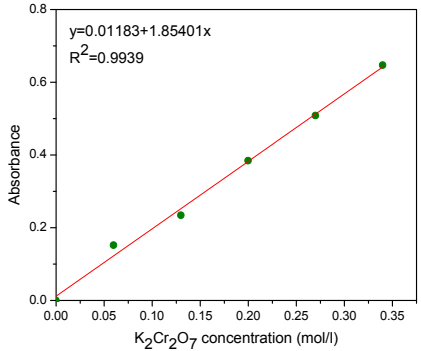

(b)

Figure 6. Calibration curve for (a) $\mathrm{Cu}^{2+}$ and (b) $\mathrm{Cr}^{6+}$
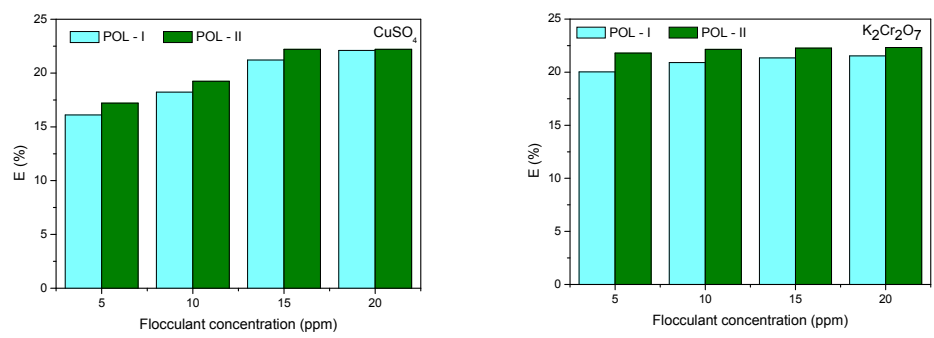

Figure 7. Heavy metals removal efficiency as a function of flocculant concentration

The heavy metals removal performance is presented in terms of "efficiency" calculated as follows:

$E(\%)=\frac{C_{0}-C_{1}}{C_{0}} \times 100$ 
Heavy Metals Removal from Contaminated Water using Poly(Acrylamide-coAcrylic Acid)-Sodium Alginate Flocculant Obtained by Radiation Processing

where $\mathrm{C}_{0}$ is the initial heavy metals concentration $\left(\mathrm{Cu}^{2+}\right.$ and $\left.\mathrm{Cr}^{6+}\right)$ and $\mathrm{C}_{1}$ is the heavy metals concentration after flocculation.

Four concentrations from each flocculant were used, obtained from stock solutions of $0.1 \%, 5,10,15$, and $20 \mathrm{ppm}$, respectively. In Figure 7 the heavy metals removal efficiency is represented as a function of the flocculant concentration and it is observed that the flocculation efficiency has increased with the concentration of flocculant.

\section{CONCLUSIONS}

This study was carried out to illustrate the synthesis of poly[acrylamide-co-acrylic acid]-sodium alginate flocculants in presence and absence of initiator under the effect of electron beam irradiation. For the samples obtained this way it was found that the conversion coefficient (CC) and residual monomer concentration $\mathrm{M}_{\mathrm{r}}$ shows a linear dependence on radiation dose, while the intrinsic viscosity $\left(\eta_{\text {intr. }}\right)$, the linearity constant $\left(\mathrm{k}_{\mathrm{H}}\right)$ and the molecular weight $\left(\mathrm{M}_{\mathrm{w}}\right)$ shows good values only in the middle of dose range. From the flocculation studies, in order to determine the heavy metals removal efficiency, it is observed that the flocculation efficiency has increased with the concentration of flocculant and also that the best results correspond with the use of flocculants obtained in the presence of initiators.

\section{REFERENCES}

Alyuz, B. and Veli, S. (2009), "Kinetics and equilibrium studies for the removal of nickel and zinc from aqueous solutions by ion exchange resins", Journal of Hazardous Materials, 167(1-3), 482-488.

Bessbousse, H., Rhlalou, T., Verchere, J.F. and Lebrun, L. (2008), "Removal of heavy metal ions from aqueous solutions by filtration with a novel complexing membrane containing poly(ethyleneimine) in a poly(vinyl alcohol) matrix", Journal of Membrane Science, 307(2), 249-259.

Brostow, W., Lobland, E.H.E., Pal, S. and Singh, R.P. (2009), "Polymeric flocculants for wastewater and industrial effluent treatment", Journal of Materials Education, 31, 157-166.

Guclu, G., Gurdag, G. and Ozgumus, S. (2003), "Competitive removal of heavy metal ions by cellulose graft copolymers", Journal of Applied Polymer Science, 90(8), 2034-2039.

Iva, R. and Zeiner, M. (2008), "Determination of extractable chromium from leather", Monatshefte fuer Chemie, DOI 10.1007/s00706-008-0026-1.

Liu, F.N., Zhang, G.L., Meng, Q. and Zhang, H.Z. (2008), "Performance of nanofiltration and reverse osmosis membranes in metal effluent treatment", Chinese Journal of Chemical Engineering, 16(3), 441-445.

Meunier, N., Drogui, P., Montane, C., Hausler, R., Mercier, G. and Blais, J.F. (2006), "Comparison between electrocoagulation and chemical precipitation for metals removal from acidic soil leachate", Journal of Hazardous Materials, 137(1), 581-590.

Richardson, R.K. and Kasapis, S. (1998), "Rheological methods in the characterization of food biopolymers", Developments in Food Science, 39, 1-48.

Shaoping, Y., Shiyu, F., Hao, L., Yiming, Z. and Xueyun, L. (2011), "Hydrogel Beads Based on Carboxymethyl Cellulose for Removal Heavy Metal Ions", Journal of Applied Polymer Science, 119, 1204-1210.

Sprynskyy, M. (2009), "Solid-liquid-solid extraction of heavy metals $(\mathrm{Cr}, \mathrm{Cu}, \mathrm{Cd}, \mathrm{Ni}$ and $\mathrm{Pb}$ ) in aqueous systems of zeolite-sewage sludge", Journal of Hazardous Materials, 167(2-3), 1377-1383.

Tripathy, T. and De, B.R. (2007), "Biodegradable Flocculants Based on Partially Hydrolysed Starch-gPolyacrylamide", Journal of Physical Sciences, 11, 139-146.

Ucer, A., Uyanik, A. and Aygun, S.F. (2006), “Adsorption of $\mathrm{Cu}(\mathrm{II}), \mathrm{Cd}(\mathrm{II}), \mathrm{Zn}$ (II), $\mathrm{Mn}$ (II) and Fe(III) ions by tannic acid immobilised activated carbon", Separation and Purification Technology, 47(3), 113-118.

Xie, C., Feng, Y., Cao, W., Teng, H., Li, J. and Lu, Z. (2009), "Novel Biodegradable Flocculating Agents Prepared by Grafting Polyacrylamide to Konjac", Journal of Applied Polymer Science, 111, 2527-2536.

Zeynali, M.E. and Rabbii, A. (2002), "Alkaline Hydrolysis of Polyacrylamide and Study on Poly(acrylamideco-sodium acrylate) Properties", Iranian Polymer Journal, 11, 269-275.

Wen, T., Qu, F., Li, N.B. and Luo, H.Q. (2013), "A facile, sensitive, and rapid spectrophotometric method for copper(II) ion detection in aqueous media using polyethyleneimine", Arabian Journal of Chemistry, http://dx.doi.org/10.1016/j.arabjc.2013.06.013. 